\title{
Ergonomics of Field Machines
}

\section{Hon Keung YAU*}

Department of Systems Engineering and Engineering Management, City University of Hong Kong, Kowloon Tong, Kowloon, Hong Kong

*Corresponding author: Hon Keung YAU, Department of Systems Engineering and Engineering Management, City University of Hong Kong, Kowloon Tong, Kowloon, Hong Kong. E-mail: honkyau@cityu.edu.hk

Rec Date: May 3 2014; Acc Date: May 3 2014; Pub Date: May 52014

Copyright: ( 2014 Hon Keung YAU. This is an open-access article distributed under the terms of the Creative Commons Attribution License, which permits unrestricted use, distribution, and reproduction in any medium, provided the original author and source are credited.

\section{Introduction}

The effects of different frequencies and magnitudes of vibration on aspects of human performance, such as manual control, vision, perception and cognition are being concerned. Surveys and investigations were done on manual tracking and visual acuity during vibration exposure and have been well-studied with documented.

It has been confirmed that vibration does not significantly affect human performance on straightforward perceptual tasks such as auditory or visual detection of signals. In the following section, the potential health and safety impacts of whole-body vibration would be explicated.

\section{Manual Tasks and Tracking Performance Studies Review}

The range of vibration frequency which is believed significant for health, comfort and perception is 0.5 to $80 \mathrm{~Hz}$ [1]; the investigation of this project will be limited to range 0.5 to $10 \mathrm{~Hz}$ which is the most common vibration frequency in daily life.

Tracking errors generally increased while the vibration magnitude increased, and the error was most responsive to $5 \mathrm{~Hz}$ of $\mathrm{z}$-axis vibration [2]. Also tracking performance of vertical vibration have been found that in range of frequencies between 2 and $12 \mathrm{~Hz}$, came with the maximum reduction occurring at the lowest of the frequency range. It can be concluded that the vibration magnitude had a superior consequence on tracking performance than the vibration frequency did [1].

Manual tasks performance is disturbed in the range of whole-body resonance. This range is between 2 and $10 \mathrm{~Hz}$ for vertical vibration. From the result of a series of experiments, different manual tasks performance would be affected by of different frequencies and amplitudes of vibration. Such as, for writing tasks, it is most difficult to perform with vertical vibration frequencies between 4 and $6 \mathrm{~Hz}$. Also, tracking error at specified vibration frequencies was showing linear trends approximately with vibration magnitude, while $5 \mathrm{~Hz}$ vibration has the steepest slope.

\section{Visual Performance Studies Review}

Vibration would procure relative movement between the retina and the visual display. It may produce an unclear image and degrade visual performance. These movements may happen when there is vibration of display, vibration of observer, and vibration of both display and observer.

The early studies indicated that visual performance declined with increasing vibration magnitude, but there was no agreement on how vibration frequencies affected visual performance. For vertical vibration, there were 3 frequency-related factors that influence visual performance:

a. Compensatory tracking eye movements, which protect visual acuity for low frequency vibration below about 1 to $2 \mathrm{~Hz}$,

b. Amplification or attenuation of vibration from the seat to the head, and

c. Resonances within the eye at high frequency which above $20 \mathrm{~Hz}$ [2]

Visual performance was affected by vibration frequencies range 10 to $25 \mathrm{~Hz}$ [3]. By comparing vibration of observer only and vibration of display only, vibration would affect observer while frequency is over 10 $\mathrm{Hz}$; and vibration would affect acuity while display frequency is below $10 \mathrm{~Hz}$ [4].

Studies also have done on the transmission of vibration from vibration platform (seat) to head whether it would produce an impact on performance of reading of numerical displays. It was found that the performance of reading errors followed linear direct proportional with increasing vibration magnitude. The most sensitivity for reading errors arose with $\mathrm{z}$-axis vibration frequencies around $11 \mathrm{~Hz}$.

In testing of the relationship between reading distance and reading errors caused by vibration, low frequency vibration around $3.15 \mathrm{~Hz}$ was found to cause reading errors only at short reading distances. Higher frequencies around $16 \mathrm{~Hz}$ affected reading accuracy at any distances, with direct proportional linear increasing in error with vibration magnitude $[5,6]$.

For the vibration frequency transmitted from the vibration platform which is below $2 \mathrm{~Hz}$, the transmissibility is coherent and there is no significant body resonance. The maximum transmission occurs at frequency range 2 to $10 \mathrm{~Hz}$, which is the major natural frequency of the human body and primary resonance occurs. From 10 to $20 \mathrm{~Hz}$, secondary body resonances may occur, and, above $20 \mathrm{~Hz}$, the vibration is weakened by the body structures and the transmission is less than which in the case of below $2 \mathrm{~Hz}$ [7].

Vibration is believed having a negative effect on complex cognitive tasks; however, the vibration frequency and magnitude reliance have not been proven. Also, vibration leads comfort problems (such as perceptual) as well as health problems (such as cognitive). Comfort problem is entirely subjective which cannot be measured by observation, questionnaire is needed to help.

\section{Effect of Vibration to Human Perceptual Performance}

Basically, vibration can be divided into 2 groups:

a Free vibration 
Page 2 of 2

It occurs on an object which vibrates without external force affect, and vibrates with its natural frequency.

b Forced vibration

It occurs due to external force. It the external added frequency is same as the object's natural frequency, resonance occurs.

Resonance produces a large amount of vibration inside the object structure which may harm the object itself and should be avoided. Each part of human body has their own natural frequency and it varies according to mass of body (Table 1).

In the design of questionnaire of the survey of this project which measure the uncomfortable of human body due to vibration, it includes the area which presented in the following table:

\begin{tabular}{|l|l|l|}
\hline Body part & $\begin{array}{l}\text { Resonance } \\
\text { frequency } \\
\text { (Hz) }\end{array}$ & Symptoms \\
\hline Whole body & $4-5,10-14$ & General discomfort \\
\hline Upper half of body & $6-10$ & \\
\hline $\begin{array}{l}\text { Head } \\
\text { Eye balls } \\
\text { Skull, jaw } \\
\text { Throat }\end{array}$ & $\begin{array}{l}5-20 \\
1-100, \text { Mostly above } \\
8\end{array}$ & $\begin{array}{l}\text { Visual difficulties } \\
\text { Taximum at } 20-70 \\
100-200\end{array}$ \\
\hline $\begin{array}{l}5-20 \\
\text { Shoulder }\end{array}$ & $2-10$ & \\
\hline Lower arm & $16-30$ & \\
\hline Hands & $4-5$ & Chest pain \\
\hline $\begin{array}{l}\text { Body trunk } \\
\text { Heart } \\
\text { Chest } \\
\text { Stomach } \\
\text { Abdominal } \\
\text { Bladder }\end{array}$ & $\begin{array}{l}3-7 \\
4-6 \\
60\end{array}$ & $\begin{array}{l}\text { Urgency } \\
3-6\end{array}$ \\
\hline Heart and blood vessels & $\begin{array}{l}4-8 \\
10-18\end{array}$ \\
\hline Bain & $2-20$ & Sports vomiting disease \\
\hline
\end{tabular}

